\title{
Obtain and Application of Surface-active Substance on the Base of Products Refination of Cotton Seed Oil
}

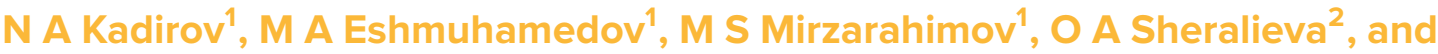 \\ $J \mathbb{K}$ Artikova $^{3}$ \\ ${ }^{1}$ Tashkent state technical university, Tashkent, Uzbekistan \\ ${ }^{2}$ Tashkent's chemical technological institute, Tashkent, Uzbekistan \\ ${ }^{3}$ South Kazakhstan state university, Chimkent, Kazakhstan
}

\section{Abstract}

The article the results of investigation on obtaining of surface-active substance -SAS on the waste cotton oil for drilling of wells and intensification of the flotation process are presented. The main component of new SAS are waste, cotton oil refinery and chemical plants. SAS have hudrophobization (waterproof) action on easy-swelling rocks (clays, argellites, alevrolits). Direct water emulsions obtained from reagents have

Corresponding Author:

N A Kadirov

abdusamig@rambler.ru

Received: 25 October 2019

Accepted: 15 November 2019

Published: 25 November 2019

Publishing services provided by Knowledge E

(c) N A Kadirov et al. This article is distributed under the terms of the Creative Commons

Attribution License, which permits unrestricted use and redistribution provided that the original author and source are credited.

Selection and Peer-review under the responsibility of the AgroSMART 2019 Conference Committee. low viscosity, high stability and low filtration index. There reagents have influence at drilling tools (that is they increase the life of drilling bits and diamond bits) [1, 2]. The study flotation enrichments of copper-molybdic ore is revealed characteristic foam-former and collector surface-active substances (NA-1) and is simulation one oily provided creation without minerals fields extraction of gold and color metals has been determined. Optimal conditions of the syntheses: ratio of main components, time of reaction, temperature and concentration have been determined. The comparison of new SAS with other foreing analogies was carried out. The main colloidal-chemical characteristic of synthesized SAS: surface activity, adsorption, viscosity, concentration of micelle- formation have been determined. Technology of obtain of anion surfaceactive substances from local organic raw material was elaborated, which by qualitative characteristics is a substitute of the import reagent collector and foam-former $[4,5]$. Dependence on obtained product from the temperature of the process, time of reactions, ratio of initial components optimal concentration of $\mathrm{NaOH}$ was investigated. The foam forming ability of the new reagents in comparison with standard reagent T-92 was determined and it was shown that by best ability of forms destruction the methyl syloxane's liquid and mineral oil have possessed.The intensifications of the process of flotation's enrichment of copper-molybdic ore with using new obtain reagent NA-1 was offered.

\section{Introduction}

Surface-active substance use in different spheres industrial production and everyday life of man. In depending on chemical nature and composition SAS subdivided on five main classes: anion -active, cathions- active, non- ionogene, amphoteric and polymeric 
[1]. SAS are use for obtain of emulsion-drilling solution with low density, which are used at drilling of wells oil, gas and solid minerals fields. SAS is formation of true molecular solutions at low concentrations as well as thermodynamic stable micelles solutions at high concentrations. Anion SAS are use for flotation enrichments of color ore to foamformer and collector surface-active substances, is simulation one oily provided creation without minerals fields extraction of gold and color metals.

\section{Materials and Methods}

The methods of the syntheses of surface-active substance SAS are is most cases based on well-known reactions of organic chemistry. The methods of investigation are based on methods of determination of o colloidal-chemical characteristic (surfaceactivity, adsorption, viscocity, concentration of micelle formation) [4].

\section{The Study of the Elaborated Synthesis and Obtain Anion SAS}

The syntheses new SAS was carried in laboratory conditions. The conditions of syntheses (the temperature, time, concentration) and ratio of components were determined. On the base of carring out experiments the optimum parameters of obtained surfaceactive substance (NA-1), also were determined. Experimental samples of SAS -- an flotoreagents, were obtained which were used in combination with traditional reagent. Elaborated technology of obtain and using SAS is concluded in that that under their production is used local organic raw material. By proposed technology obtaine anion's SAS (NA-1), which by qualitative characteristics of import reagent: T-92, has been provided offered intensification of enrichment process ore by method flotation with using reagentcollectors and foam-formeds (NA-1, NA-2) on base of the local secondary product -waste of the process of distillations fatty acids of cotton soapstoks (low composition of the distilled fatty acids is presented). Oil fatty plants of the republic Uzbekistan wastes of distillations the fatty acids cotton soapstok's are produced. Results of researches of composition wastes of distillations of the fatty acids(DFA) have shown that they consiste from $52--60 \%$ carbon fatty acids, which used for obtaine SAS.

Composition of distilled fatty acids from lokal raw materialsl for obtaine of surfaceactive substance (SAS) has been investigation (Tabl. 1) [1].

One of the priority problems costing before is mining branch of the republic is an introduction leading technology in process the mining enrichments of ore, containing 
TABLE 1: Physics-chemical characteristics and composition of distilled fatty acids (DFA).

\begin{tabular}{|c|c|c|c|c|c|}
\hline No. & Factions & $\begin{array}{l}\text { Output (\%,) to } \\
\text { weight of DFA }\end{array}$ & $\begin{array}{l}\text { temperature of } \\
\text { the melting, }{ }^{\circ} \mathrm{C}\end{array}$ & Colour & $\begin{array}{l}\text { Composition to } \\
\text { factions }\end{array}$ \\
\hline 1 & $\begin{array}{l}\text { Part is not forming } \\
\text { soap }\end{array}$ & $21--22$ & -- & Dark-brown & $\begin{array}{l}\text { Hydrocarbons: } \\
\mathrm{C}_{27}, \mathrm{C}_{29}, \mathrm{C}_{31}, \mathrm{C}_{28} \text {, } \\
\mathrm{C}_{30}, \mathrm{C}_{32} \text { alcohols } \\
\text { and sitosterin }\end{array}$ \\
\hline 2 & Fatty-acid part & $52--55$ & -- & Black & $\begin{array}{l}\text { Fatty acids } \\
\mathrm{C}_{16}-\mathrm{C}_{18}\end{array}$ \\
\hline 3 & Phenols & $22--23$ & 180--181 & $\begin{array}{l}\text { From brown } \\
\text { before dark-brown }\end{array}$ & Phenols \\
\hline
\end{tabular}

color and precious metals for the reason reductions of the prime cost of the final product. One of the ways of the achievement to afore said purpose is a change of import Russian chemical preparation on SAS from local organic substances.

For flotation's enrichments of ore color and precious metals use the surface-active material: spume form of the salt carbon acids, butylksantogenate potassium (BKP) and reagent $\mathrm{T}-92$.

Have been used elaborated technology of the obtain surface-active substances on the base of local secondary of chemical and oil fatty plants republics of Uzbekistan was used [7].

SAS obtained in laboratory condition, is selected correlations main source component, as best condition of the syntheses (temperature, time of reaction, concentration). On collected by us experimental to installation on designed optimum condition new SAS (NA-1) was produced test pasts of flotoreagent's, which were tested in combination with traditional reagents. Novelty proposed technology of obtained and using SAS concluded in fact that at their production local organic raw material is used. By proposed technology obtain of anion SAS (NA-1) is provided, which by qualitative characteristics is substitute of reagent: collector BKK (the price 1820 \$. USA for $1 \mathrm{t}$ ) and foam- formed T-92 (the price 640 \$ USA for $1 \mathrm{t}$ ).

It is offered intensification of process of the ores enrichment by method flotation with using reagent-collectors and foam --formers (NA-1, NA-2) on base local secondary product -- cube remainder of the process of distillation of fatty acids of cotton soapstok's (CRDFA).

At elaborating of new technology the special attention was devoted strove; strived to intensification of flotation process of the ores enrichment, changing of import reagent (BKK, T-92) on reagents obtain from local raw materials with aim in finally provide economy currency of the republic. 
We have patent on inventor of technology receive the reagent NA-1. The important stage our innovation is elaboration of technical documentation (the technological regulation and standard specifications), montage of experiential-industrial technological installation and output of experienced- industrial party reagent NA-1, NA-2.

In department by enrichment of copper-molubdenium ore tests two samples foam formers (NA-1, NA-2) on the ore of field "Kalmakir" (the scheme flotation is presents on Figure 1), entering on processing on copper concentrating mill (CCM), were carrier out. The chemical composition this ore is presented in table 2 .

The samples of foam-formers NA-1, NA-2 present them self liquids dark-brown colour, without scent, well dissolved in water. The results of the carried out tests have shown practicability of the use new foam-former surface-active substances NA-1 in lieu thereof (and in combinations T-92), as well as need of the undertaking (its) further introduction at enrichment of copper-molybdic ore.

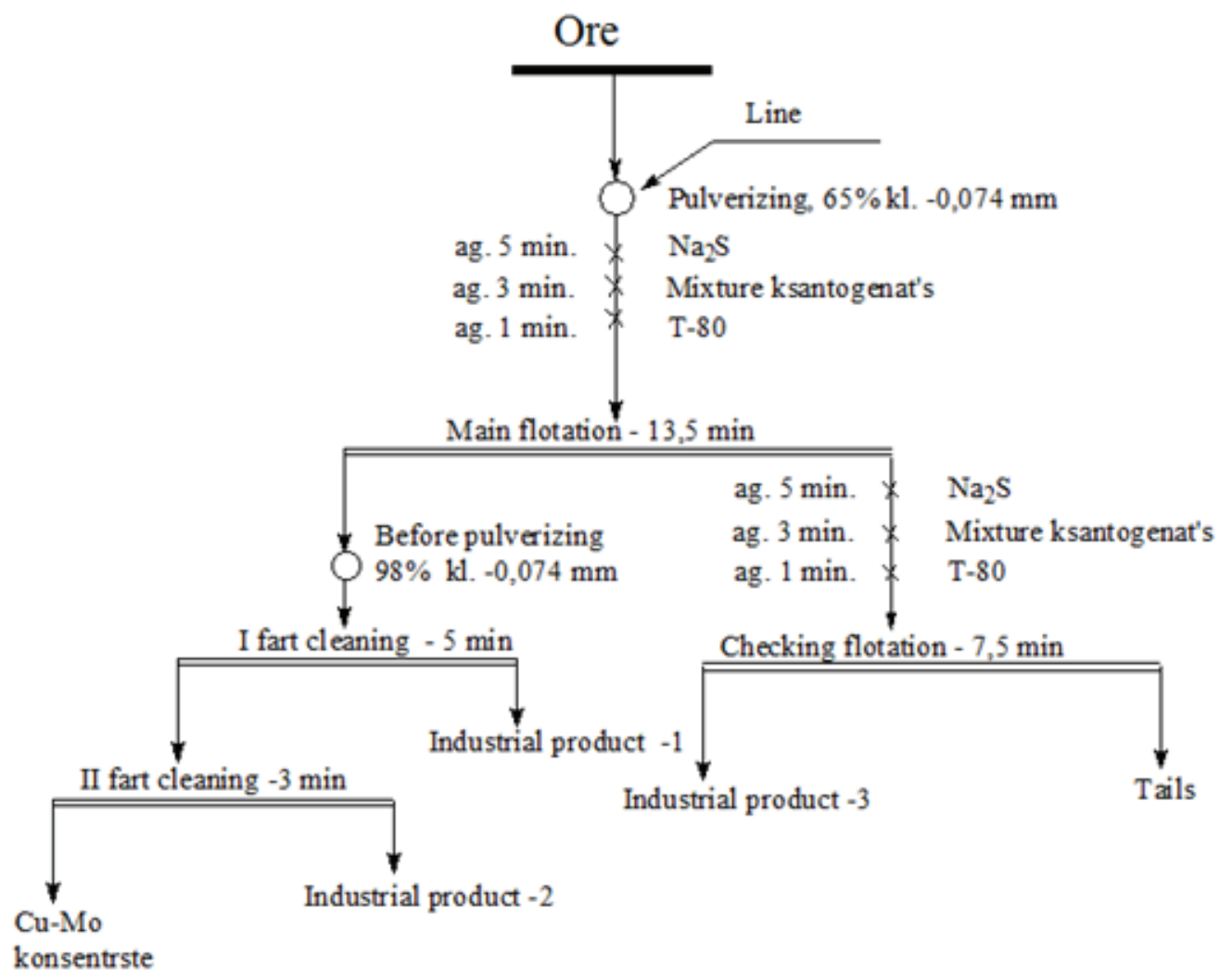

Figure 1: Scheme of flotation enrichment of copper ore deposit feild Kalmakir.

TABLE 2: The chemical composition of ore.

\begin{tabular}{l|c|c|c|c|c|c|c|c|c|c|}
\multicolumn{10}{c|}{ Contents, \% } & \multicolumn{1}{c|}{ Sulfide ore, \% } \\
\hline $\mathrm{Cn}$ & $\mathrm{Mo}$ & $\mathrm{CaO}$ & $\mathrm{MgO}$ & $\mathrm{Fe}$ & $\mathrm{S}$ & $\mathrm{SiO}_{2}$ & $\mathrm{A1}_{2} \mathrm{O}_{3}$ & $\mathrm{An}$ & $\mathrm{Ag}$ & \\
\hline 0,41 & 0,0042 & 1,62 & 1,59 & 5,80 & 3,05 & 56,40 & 13,12 & 0,56 & 3,50 & 94,73 \\
\hline
\end{tabular}


With aim of determination of foaming characteristics, of elaborated by us reagents the laboratory investigation in open cycle (table 2), in comparison with standard foamformer T-92, at this consumption of initial foam-former was equaled $30,0 \mathrm{~g} / \mathrm{t}$, but in their mixture it was equaled: NA-1-15,0 g/t + T-92-15,0 g/t and NA-2-15,0 g/t + T-92-15,0 g/t, by the regime accepted on plant [6]:

1. dispersion of ore grind: $+0,21 \mathrm{~mm}--5,0 \%$,

2. $0,071 \mathrm{~mm}--60,5 \%$;

3. $\mathrm{pH}--10,8$;

4. consumption of ksantogenate $-25,0 \mathrm{~g} / \mathrm{t}$;

5. consumption of mineral oil -- 7,0 g/t.

The rezults of experiences as well as visual observations for the process of flotation have shown that new reagents have possessed by foam-forming ability closed to standard in comparison with the known reagent T-92.

At consumption foam-former $30,0 \mathrm{~g} / \mathrm{t}$ in experience with NA-1 formation of foam was slower; yield the quick-and-dirty concentrate also was lower on $2,42 \%$ and extraction of copper from concentrate was lower on 7,86 \% in comparison with T-92.

In experience from mixture of foam formers NA-1-15,0 g/t + T-92-15,0 g/t yield of the main concentrate (on 1,55 \%) and extraction of copper (on 5,91\%) are lower at comparison with experience on $\mathrm{T}-92-30,0 \mathrm{~g} / \mathrm{t}$; the flotation front is displaced in side checking flotation: yield the main concentrate -- 2,43\%, controlled concentrate -- 5,11 $\%$; extraction of copper from concentrate of controle flotation was equaled -- 23,76\%.

NA-2 possesses the lower foam formation ability than NA-1. Results of the carring out tests have shown practicability of carring out further experienced tests of foams-formes on base CRDFA for flotation of copper-molubdenium ore processing on factory [7].

The carried out investigations have shown that synthesized surface-active substance NA-1 can by replaced on import foam-former: T-92.

The earlier carried out investigations of characteristic of different foam formers shown that for maximal extraction of metals by method flotation the foam-formation and time of life's foam solution SAS must be optimal and did not to exceed 35--40 s. In connection with need of the selection of optimal time of foam life and regulation of foam formation of NA-1 investigations was carried out by destruction foam layer by using of different foam extinguishers. It was shown that by best ability of destruction of foams polimethylsiloxane liquid and sivas oil (Figure 2) have possessed. 
TABLE 3: Results of laboratory experiences by possibility of using of foam formers NA-1, NA-2 (on the base of CrDFA) on ores of deposit "Kalmakir".

\begin{tabular}{|c|c|c|c|c|c|c|}
\hline \multirow[t]{2}{*}{ No. } & \multirow[t]{2}{*}{ Product } & \multirow[t]{2}{*}{ Yield, \% } & \multicolumn{2}{|c|}{ Copper, \% } & \multirow{2}{*}{$\begin{array}{l}\text { Expense of foam } \\
\text { former, } g / t\end{array}$} & \multirow{2}{*}{$\begin{array}{l}\text { Conditions of } \\
\text { experiments }\end{array}$} \\
\hline & & & $P$ & $E$ & & \\
\hline \multicolumn{6}{|c|}{ Foaming agent T-92 } & \\
\hline \multirow[t]{6}{*}{ I } & Main flitation concentrate & 3,98 & 7,380 & 72,78 & T-92-30,0 & \\
\hline & $\begin{array}{l}\text { Control flotation } \\
\text { concentrate }\end{array}$ & 4,05 & 1,350 & 13,55 & & $\mathrm{pH}--10,8$ \\
\hline & Black concentrate & 8,03 & 4,340 & $(86,33)$ & & \\
\hline & Waste & 91,97 & 0,060 & 13,67 & & \\
\hline & Ores & 100,0 & 0,404 & 100,0 & & \\
\hline & \multicolumn{5}{|c|}{ Foaming agent HA-1 } & \\
\hline \multirow[t]{5}{*}{2} & Main flitation concentrate & 3,0 & 8,980 & 66,87 & HA-1-30,0 & $2060 \mathrm{~g} / \mathrm{t}$ \\
\hline & $\begin{array}{l}\text { Control flotation } \\
\text { concentrate }\end{array}$ & 2,61 & 1,790 & 11,60 & & $\begin{array}{l}\text { consuption } \\
\text { reagent: -- 25,0 } \\
\mathrm{g} / \mathrm{t}\end{array}$ \\
\hline & Black concentrate & 5,61 & 5,635 & 78,47 & & \\
\hline & Waste & 94,39 & 0,092 & 21,53 & & $7,0 \mathrm{~g} / \mathrm{t}$ \\
\hline & Ores & 100,0 & 0,403 & 100,0 & & \\
\hline \multirow[t]{6}{*}{3} & Main flitation concentrate & 2,43 & 10,330 & 62,07 & $\begin{array}{c}\text { Mixture: HA-1-15,0 } \\
\quad+\mathrm{T}-92-15,0\end{array}$ & \\
\hline & $\begin{array}{l}\text { Control flotation } \\
\text { concentrate }\end{array}$ & $5, \Pi$ & 1,880 & 23,76 & & \\
\hline & Black concentrate & 7,54 & 4,600 & 85,83 & & \\
\hline & Waste & 92,46 & 0,062 & 14,17 & & \\
\hline & Ores & 100,0 & 0,404 & 100,0 & & \\
\hline & \multicolumn{5}{|c|}{ Foaming agent HA-2 } & \\
\hline \multirow[t]{5}{*}{4} & Main flitation concentrate & 1,60 & 12,160 & 48,39 & HA-2-30,0 & \\
\hline & $\begin{array}{l}\text { Control flotation } \\
\text { concentrate }\end{array}$ & 3,56 & 3,430 & 30,37 & & \\
\hline & Black concentrate & 5,16 & 6,140 & 78,76 & & \\
\hline & Waste & 94,84 & 0,090 & 21,24 & & \\
\hline & Ores & 100,0 & 0,402 & 100,0 & & \\
\hline \multirow[t]{5}{*}{5} & Main flitation concentrate & $2,81$. & 8,850 & 61,68 & $\begin{array}{c}\text { Mixture: HA-2-15,0 } \\
\quad+\mathrm{T}-92-15,0\end{array}$ & \\
\hline & $\begin{array}{l}\text { Control flotation } \\
\text { concentrate }\end{array}$ & 4,05 & 2,280 & 22,90 & & \\
\hline & Black concentrate & 6,86 & 4,970 & 84,58 & & \\
\hline & Waste & 93,14 & 0,067 & 15,42 & & \\
\hline & Ores & 100,0 & 0,403 & 100,0 & & \\
\hline
\end{tabular}

Foam formation must be optimal since as a rule it's surplusal foam-formation is not advisable in some technological process. 
At elaboration of technology on obtain NA-1 in industrial scale the technological regime of obtaining on experimental- industrial installation, which was collected on Kattakurgan oil fatty plant of Uzbekistan. In experimental investigation by working out technology of the obtain surface-active substance NA-1 dependence on the yield of the product: the temperature of the process, time to reaction, ratio of initial component was studied. At determination of the maximum yield of the final product it was determined that with increasing temperature before $100{ }^{\circ} \mathrm{C}$ for yield surface-active substance NA-1 was maximal. The optimal concentration of the solution containing hydroxide sodium at which was observed maximal yield of surface-active substance NA-1 was 15--20 \%.

At elaboration of the technological rejime of obtain SAS NA-1 it was determined that:

1. two parts of process, where first stages is a preparation of the water solution of hydroxide sodium with participation of the spent catalyst of acetylene hydrogenation;

2. high reactionary ability of the spent catalyst of acetylene hydrogenation.

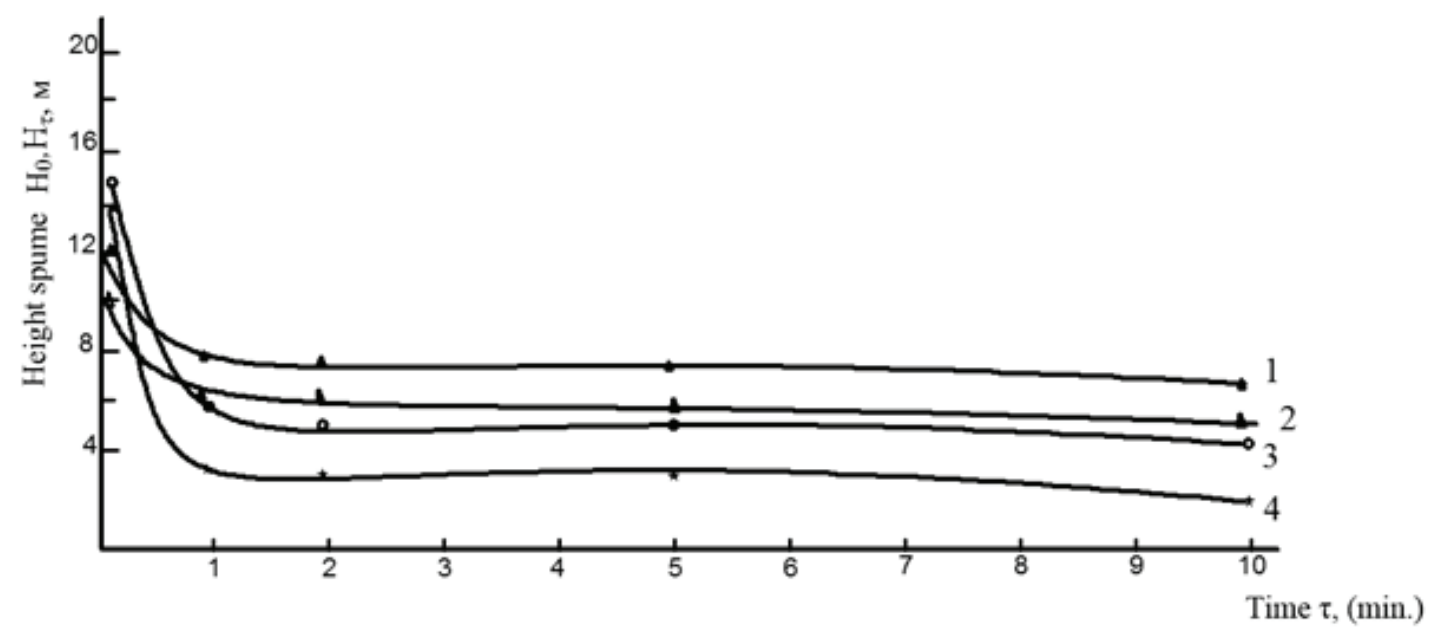

Figure 2: The kinetic curves of the destruction of foam layer of water solution SAS NA-1 by additives (1\%) of the foamy extinguishers: 1 -- parafin; 2 -- rubber mite; 3 -- sivas oil; 4 -- polimethylsiloxane liquid.

TABLE 4: Surface tension of water solution SAS.

\begin{tabular}{|l|c|c|c|}
\hline Concentration, \% & \multicolumn{3}{|c|}{ Value of the surface tention water solution } \\
\hline & «NA-1» & T-92 & OП-10 \\
\hline 0,01 & 60,7 & 61,2 & 50,9 \\
\hline 0,05 & 42,1 & 42,6 & 41,6 \\
\hline 0,10 & 38,0 & 38,6 & 41,0 \\
\hline 0,25 & 36,2 & 36,9 & 36,1 \\
\hline 0,5 & 35,9 & 36,2 & 35,6 \\
\hline 1,0 & 34,8 & 35,1 & 35,5 \\
\hline
\end{tabular}


Dependence on hydrolysis reactions from duration of process, intensity and time of the mixing has been determined.

Study of colloidal-chemical characteristic surface-active substances has allowed to conclusion that obtained at hydrolysis sodium (the presence of perfected catalyst) preparates are superficially-active compounds of semi-colloidal type able to formation true molecular solution low concentration and colloidal thermodynamic stable micelleous solution -- at high concentration.

Carried out investigations of tribologic characteristic of SAS NA-1 on machine of friction of American company "Baroid" have shown deterioration of wear-out characteristics of the solution with lubricating additives at high alkalinity $(\mathrm{pH})$ what is explained by their colloidal dissolution and devision from sticking surfaces owing to high concentrations in solution of sodium soaps.

\section{Conclusions}

Reagents on the base of waste of distillations of fatty acids cotton soapstok's are recommended use for preparing emulsion-drilling muds with low density, which are used on oil, gas and hard at drilling wells raw-minerals in zones of falling and collapsing well walls.

SAS have hudrophobization (waterproof) action on easy-swelling rocks (clays, argillites, alevrolits). Direct water emulsion obtained from reagent has low viscosity, high stability and low filtration index. This reagent has smearing influence at drilling tools (has increased the life of drilling bits and diamond cores).

At the same time the reagent is not toxical and transportable (in solid granules). The reagent can be combined with polymere-stabilizers and gravity preparations.

The reagents NA-1 and NA-2 are recommended as foam-formess for flotation process of extraction of non-ferrous and noble metals.

\section{References}

[1] Kadirov, A.A. (2015). Recept and applcation surfase-active material's. Tashkent, Tashkent State technical university, $145 \mathrm{p}$.

[2] Adamson, A., Muller, V.M. (2009). Physical chemistry of surface. World, 568 p.

[3] Ismoilov, R.I. (2017). Enrichment of copper -- molybdenum ores blowing agent based on recycled products of organic raw material. Austrian journal of technical and 
natural sciences, no. 5--6, pp. 26--28. Vienna.

[4] Scherbakova, L.N., Mahmudov, A.S., Sheralieva, O.A. (2012). The Study of colloidalchemical characteristic superficially-active materials on base gossypol resin. Vestnik of the Alle-RussIA Scientific Recearch Institute of Fats, no. 1, pp. 25--28.

[5] Ramachandra, S., Rao, S. (2004). Surface Chemistry of Froth Flotation. Flotation Surfactants, no. 3, pp. 385--478.

[6] Exerova, D., Kolarov, T., Esipova, N.E., Yankov, R., Zorin, Z.M. (2001). Foam and wetting films from aqueous cetyltrimethylammonium bromide solutions electrostatic stability. Coll. J., vol. 63, no. 1, pp. 50--56.

[7] Marjoribanks, I. (2018). Geological methods in mineral exploration and mining. London: Springer Heidelberg Dordrecht, 556 p. 